\title{
SPECIAL PROBLEMS OF FORESTS AS ECOLOGIC-ECONOMIC SYSTEMS
}

J. Barkley Rosser, Jr.

Department of Economics

James Madison University

Harrisonburg, VA 22801 USA

rosserib@imu.edu

June, 2012

\begin{abstract}
:
Ecologic-economic systems tend to exhibit greater complexity than systems that are purely ecological or economic. The interactions between the two types often generates nonlinear relations that lead to various kinds of complex dynamics that complicate management and decisionmaking regarding them. Of these, forests have characteristics that lead them to have special problems not usually encountered in the management of such systems. A central one is the long time periods involved managing forests compared to most other such systems. This means that the issues regarding determination of discount rates for valuing future outcomes are more important for forestry management than for many other systems. Also, forests generate a wider range of externalities than do most other ecologic-economic systems, with implications for various hierarchical levels of management. This paper considers the array of these problems as they appear for a variety of forestry management issues.
\end{abstract}

Acknowledgement: The author thanks M. Ali Khan for useful comments. The usual caveat applies. 


\section{Introduction}

Forests are among the world's most important ecosystems, prevailing in regions where precipitation exceeds transpiration and where temperatures are sufficiently warm and soil conditions sufficiently fertile. From the origins of humanity to modern high income economies, forests have provided a variety of services to people, including basic energy from fire, timber, food sources from various animals, and for modern societies such externalities as carbon sequestration, flood control, sources of medicines, aesthetics, and others. The development of various property rights systems and governance systems have altered how humans have interacted with forests over time.

A crucial part of this has also been the emergence of an awareness of the role of time and efforts to plan the management of forests over time. This has involved both how people choose discount rates to value amenities over time as well as how institutions allow for the expression of these discount rates in the forest management systems. Indeed, the importance of time and discount rates for forests led Irving Fisher( 1907) to use forests as a leading example in his innovative work on the role of interest rates in capital theory. Rosser (2005) has shown how complicated patterns of returns over time of various forest amenities can lead to capital theoretic paradoxes and complications within optimal management regimes.

This paper will extend these themes in various ways. We shall reconsider the optimal forestry management scheme in which the discount rate plays a central role. After reviewing some of the results previously presented, a new argument will be advanced that fits with some empirical findings (Amacher et al., 2009) and certain cases. Forests are renewable resources with distinct carrying capacities and are thus amenable to being analyzed using models that have been used for other renewable resources, particularly fisheries. As has long been understood, these are subject to backward-bending supply curves under certain conditions. We shall consider how this can arise for forest products as well, 
drawing on a few earlier observations of this (Binkley, 1993). As shown by Hommes and Rosser (2001), complex dynamics can arise for fisheries in this case, which can be seen possibly to carry over to forests also. This perspective is partly connected to an approach that emphasizes maintaining something like a near-steady state forest rather than the traditional emphasis on optimal rotation period of a forest, with this perspective arguably more tied to sustainability based on arguments by Kant (2003).

In the analysis referred to above, a crucial element in the optimal management case is the role of the discount rate. In particular, the backward-bending supply curves only occur for discount rates that are sufficiently high, meaning that as agents value the future less, these dynamic complexities become more likely to occur. This is consistent with arguments regarding chaotic dynamics appearing in dynamic optimization models with high discount rates (Mitra, 1996; Nishimura and Yano, 1996). It may be that these phenomena are more likely to occur in developing countries or areas where poorer populations inhabit forests or are otherwise heavily dependent upon them for basic amenities. It has long been argued that people in subsistence or near-subsistence conditions are more likely to be concerned with their immediate near future, thus effectively exhibiting higher discount rates that may lead to these outcomes.

The final topic of the paper will be to consider various factors influencing the formation of subjective discount rates. These will be seen to have arisen from evolutionary forces now hard-wired into modern humans as exhibited by neurological evidence. This discussion will follow arguments in Gowdy et al. (2012) and will also consider normative aspects of this in terms of sustainability concerns that are important in light of the difficult problem of deforestation that confronts many nations in the 
world today. For higher level planners of forests ethical issues must also be taken into account in the approach to selecting discount rates in these management cases (Khan, 2005; Price, 2005). ${ }^{1}$

\section{Optimal Periodicity in Forest Management}

The traditional focus of theoretical forestry economics has been to study the optimal rotation time of a forest homogeneous in age and species, with the only value of the forest being due to the timber obtainable at the time it is cut down. The first to arrive at a solution for this problem involving an expected replanting of the same species, was Martin Faustmann (1849), although this achievement published in German was long unknown outside of German language circles. The later solution of Fisher (1907) received far more attention, although it was only correct for a forest that is not replanted, with the land being essentially abandoned. Nevertheless, the Fisher solution was intuitively pleasing and simple: cut when the growth rate of the forest's tree volume equals the real rate of interest. As it was, even though Faustmann's solution would not be translated into English until 1968, Alchian (1952) and Gaffney (1957) realized the error Fisher had made, without themselves arriving at Faustmann's solution.

The obvious missing piece for this problem was the matter of unaccounted for non-timber amenities (or Non-Timber Forest Products, NTFPs). Hartman (1976) would resolve this, with the approval of Samuelson (1976a), of the following solution. Let $f(t)$ be the growth function of the wood volume over time, $T$ the optimal rotation period, $p$ the constant real price of timber, ${ }^{2} \mathrm{r}$ the assumed real

\footnotetext{
${ }^{1}$ That government forestry managers tend to favor lower discount rates due to their longer time horizons than others in governments is seen by the fact that after President Nixon imposes a cross-government $10 \%$ discount rate for public benefit-cost analyses, based on estimates of the private opportunity cost of capital (Stockfish, 1969), it was the National Forestry Service that was the first government agency that won a reprieve from this to use a much lower discount rate.

${ }^{2}$ Use of option theory to optimize in the face of stochastic processes was first suggested by Arrow and Fisher (1974) and since followed by many, starting with Reed and Clarke, 1990).
} 
interest rate, $c$ the assumed constant marginal cost of harvesting timber, and $g(t)$ the time pattern of non-timber amenities (NTFPs) valued by the decisionmaker. The equation then is

$$
\left.P f^{\prime}(T)=r p f(T)+r[p f(T)-c) /\left(e^{r T}-1\right)\right]-g(T)
$$

On the right-hand side the first term gives the Fisher solution, the second added to that gives the Faustmann solution, and the whole thing is the Hartman solution, although $\mathrm{g}(\mathrm{t})$ is left unspecified. Variations of it can move T to be shorter or longer (even to become infinite, such as if the most valuable thing in a forest is to preserve an endangered species that thrives in its old growth form). As it is, for the case of only considering timber use, the Faustmann solution implies cutting sooner than the Fisher solution so as to get the more rapidly growing younger trees planted sooner. ${ }^{3}$

While the time pattern of $\mathrm{g}(\mathrm{t})$, the NTFPs, is important, we must note that it also matters which ones get accounted for in decisionmaking. This will in turn depend on the nature of the ownership and management of a forest as well as its relationship to markets. While poor owners (or users allowed to harvest products from a forest, even if they are not owners) may simply use products for their own use, many owners of a forest, whether individuals, cooperative groups, firms, or state entities, will be selling products on markets. For some owners this will be what matters and all that matters, so that only marketable NTFPs will count in their accounting. As it is, a variety of these products can be marketed, including animal products from grazing, inputs to medicine, and even such things as rights to hunt or fish or sightsee. In addition, some owners will value non-marketed NTPFs, with such entities more likely to be cooperative or state. In such cases the basis of decisionmaking may be some inferred market value or it may be drawn from some other source, perhaps even some internal value, with, for example,

\footnotetext{
${ }^{3}$ The Samuelson approach has been generalized using turnpike theory following Samuelson's (1976b) “periodic turnpike" by Mitra and Wan (1985) and Khan and Piazza (2012). In this approach a multi-aged tree farm will be gradually adjusted to move towards a long-run optimal configuration with a uniform periodicity or rotation time as in the undiscounted case. However, if discount rates are high enough, then optimality may imply chaotic dynamics (Mitra, 1996; Nishimura and Yano, 1996; Khan and Piazza, 2011). Furthermore, this analysis confines itself to the timber use forest case only, although Asheim and Buchholz (2005) consider a somewhat more generalized case.
} 
conservation organizations focusing particularly on endangered species or carbon sequestration or flood control due to soil erosion. In some forests these goals may conflict, as for example in the US Southeast, whereas carbon sequestration and flood control and carbon sequestration improve with the age of most forests (Plantinga and $\mathrm{Wu}, 2003$ ), there may be a tradeoff regarding biodiversity if improving carbon sequestration involves a mono-species forest (Caparrós and Jacquemont, 2003).

For the rest of this discussion we shall avoid discussing these last issues. We shall assume that the relevant decisionmaker for a given forest is able to assign some sort of values to the stream of amenities coming from the NTFPs in their forests as given by their forest's particular $\mathrm{g}(\mathrm{t})$, and that it does not matter whether those valuations are based on market prices for products to be sold or are simply some internally determined valuation for the particular stream of amenities. ${ }^{4}$ As shown in Rosser (2005), varying values over time of these amenities can lead to complications in determining an optimal rotation period for a forest in the context of time discounting as built into (1).

A simple example of multiple forest products can be seen from the US National Forest in Western Montana as studied by Swallow et al. (1990). Cattle grazing can be done during the earlier years after a clearcut with the grazing benefit maximizing at 12.5 years and then declining. Figure 1 shows the time path for this grazing function as studied in this case for particular parameter values at that time, with a value of US $\$ 16.78$ per hectare being reached at that maximum point., this being a market-determined value.

\footnotetext{
${ }^{4}$ Methods of determining such non-marketed amenity values for state-owned forests are numerous, and ongoing controversy surrounds them with contingent valuation surveys widely used, but others emphasizing option values, existence values, and so forth used as well. These methods are particularly difficult in forests containing traditional populations such as in the Amazon rain forest (Gram, 2001).
} 


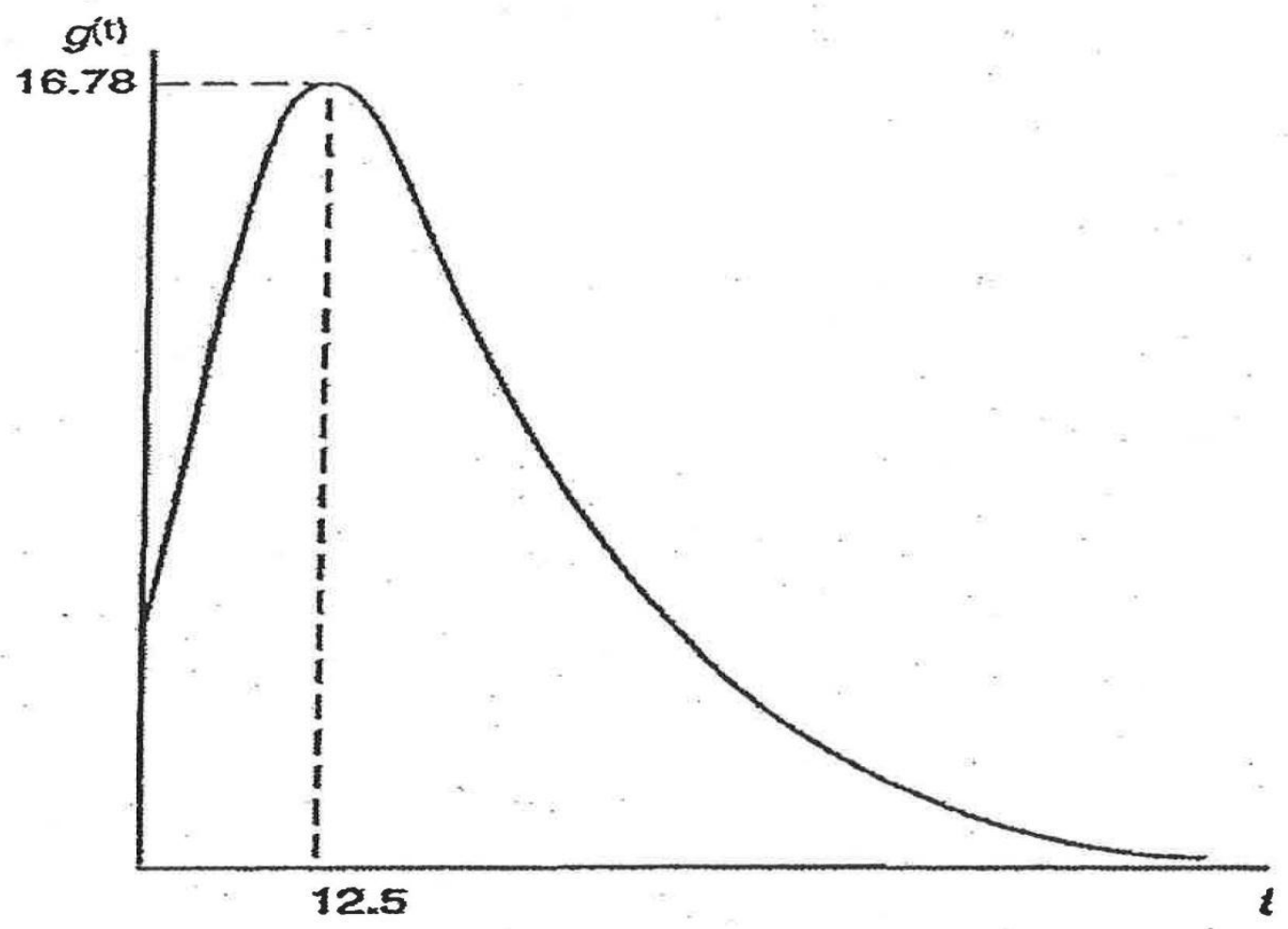

Figure 1: Grazing Benefit Function 
If one combines this with the price of timber in this forest from that time, then looking at a function of present value (PV) of those amenities over time one finds multiple maximum points over time, one early and one later arising within the appropriate Hartman equation, given $r$ and the growth function of the trees in this forest and their prices and costs of harvesting (assumed constant). In this case, one can estimate marginal opportunity costs for the forest as MOC and marginal benefits of delaying harvest as MBD, and Swallow et al. found all of this to be depicted as below in Figure 2. In this case, a global maximum occurs at 73 years, although without the grazing benefits it would occur at 76 years from a purely Faustmann equation. As it is, such non-monotonicities in net benefits over time mean that there can be osciillations in the optimal rotation period as $r$ varies as such multiple local solutions can give arise to the reswitching phenomenon (Prince and Rosser, 1985; Rosser, 2005). 


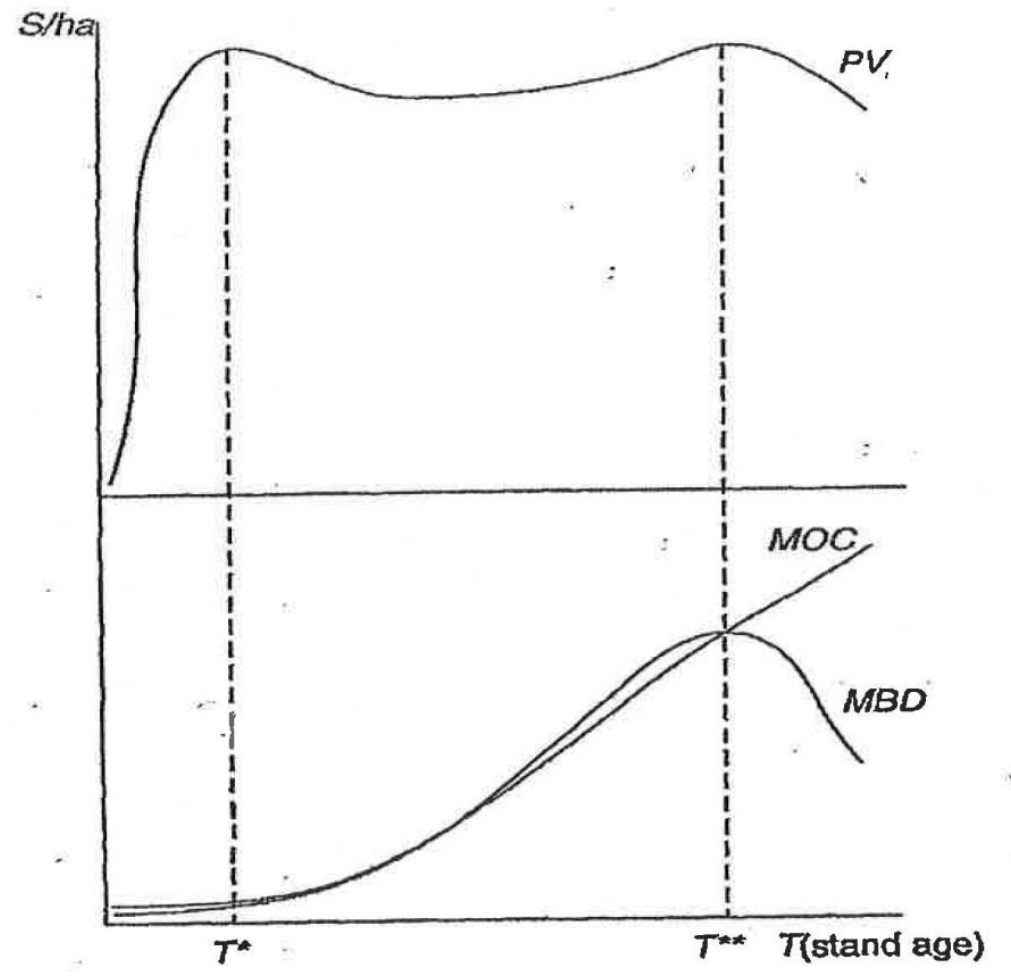

Figure 2: Optimal Hartman Rotation with Grazing 
A more complicated case can be seen in the George Washington Forest of Virginia and West Virginia of the US, which this author had the privilege of advising at one time on its land-use planning activities. These are carried out periodically through what is known as the FORPLAN process (Johnson et al., 1980; Bowes and Krutilla, 1985). US national forests are multiple use and this planning process estimates values for a variety of possible products and activities from the forests in question. ${ }^{5}$ In the case of this particular forest, the largest estimated benefits come from hunting. The time pattern of which huntable species are predominant varies over time as the growth of the forest generates varying patterns of biodiversity as dominant trees and associated animal species change over time. This is depicted in Figure 3, where deer maximize in population about 8 years after a clearcut, turkey and quail (and overall biodiversity) maximize at around 25 years after a clearcut, whereas bears maximize after the forest reaches about 60 years in age, bears preferring old growth forests with large trees (especially fallen ones). Managers of this forest must contend with the competing hunting groups in deciding what to do with various parts of the forest and when to cut them, with the more numerous deer hunters generally favoring more building of roads and frequent timber harvesting compared with the less numerous but wealthier bear hunters. This complicated pattern is depicted in Figure 3 as estimated by the author, and clearly allows for greater possibilities for oscillations of optimal rotation periods as one varies the relevant discount rate.

\footnotetext{
${ }^{5}$ Forests owned by the US government are controlled by one of two departments: Agriculture and Interior. The former are the National Forests on which many activities are allowed, including timber harvesting and hunting. The latter are National Parks in which these activities and some others are forbidden.
} 


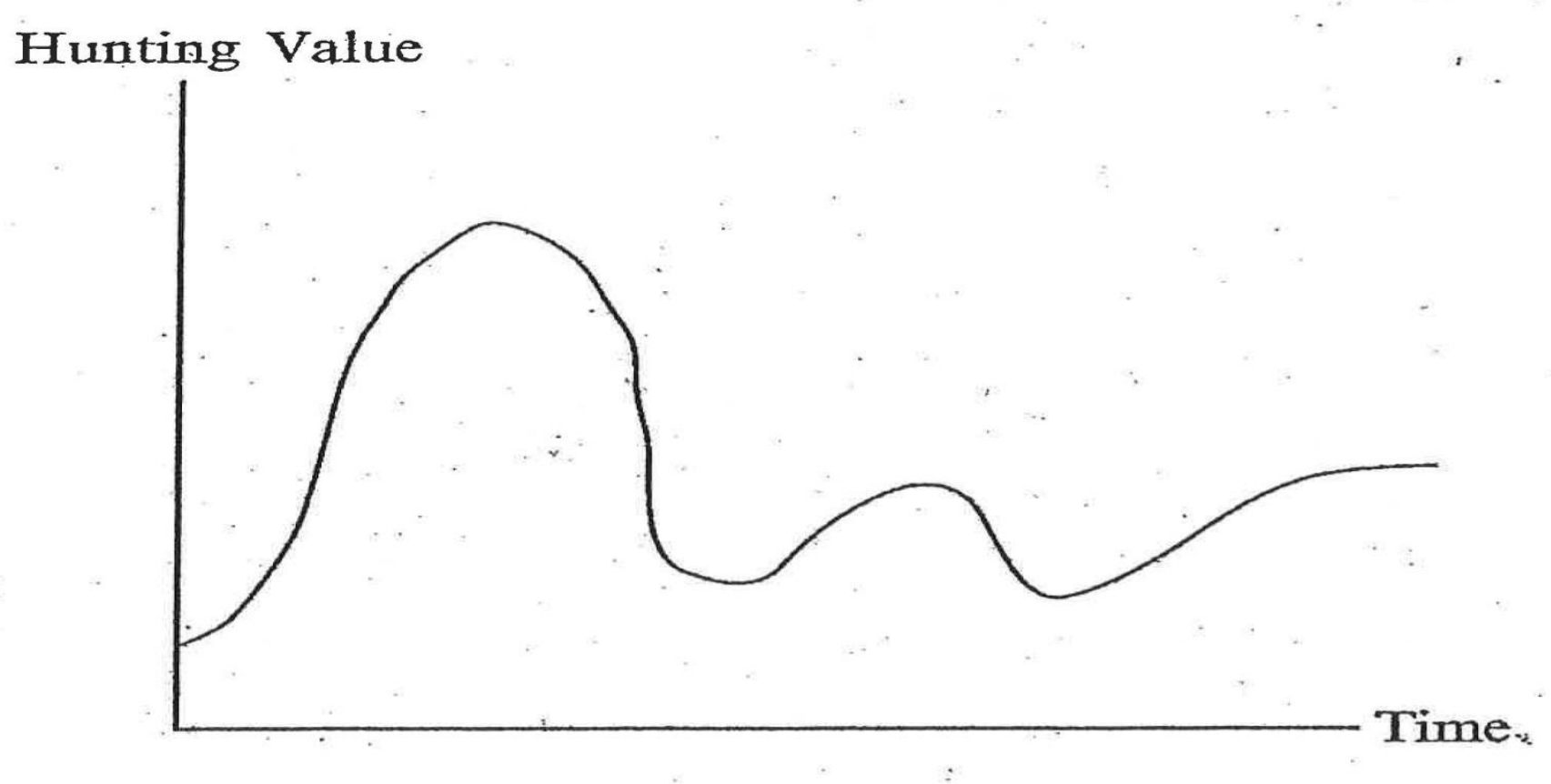

Figure 3: Virginia Deciduous Forest Hunting Amenity 


\section{Forestry Backward-Bending Supply Curves}

In sharp contrast with the previous discussion is a different approach to managing forests. Rather than planting large sections at a single time with a single species that is then allowed to grow to some specified optimal rotation time and then clearcut, to be replanted again with presumably the same species (although the Faustmann equation is sufficiently general to allow switching the land to some completely different use), this view conceives of a multi-species forest that is continually harvested in a manner that preserves it in a roughly constant state over time, that is a steady state forest, or at least an approximation thereof. Now, it must be admitted upfront that the previous analysis shows that this may not be an optimal approach from an efficiency standpoint, or that of maximizing the marketable present value of the forest. The turnpike adjustments over time in the Mitra-Wan tree farm often move the forest towards this state of homogeneity, if not necessarily. Nevertheless, such patterns may be observed in more traditional and poorer societies, where the goal may be to have a sustained flow of certain forest products, such as firewood, along with perhaps some constant availability of a particular pattern of animal species or broader biodiversity, not to mention avoiding the externality problems associated with large clearcuts such as soil erosion. Such a system may be one way to approach the goal of sustainable forest management that may also be associated with broader cultural values as articulated by $\operatorname{Kant}(2000,2003,2005)$.

Assuming that the forest is not just strictly a subsistence one with at least some product or products being sold in markets, a phenomenon that can appear is that of a backward-bending supply curve for such products. Empirical observations that support the existence of such backward-bending supply curves, for timber in particular, include a recent study of smallholder timber sales on the Amazon frontier by Amacher et al. (2009). They found a strongly negative and statistically significant elastic of supply for timber in their sample. This is finding is even stronger than the usual story of backward- 
bending supply curves, where there is usually an upward-sloping portion observed. In this case only negative elasticities were observed, although linear forms were assumed, thus ruling out the sort of non-monotonicity one observes in the more standard formulations of such supply curves.

We must note that this case does not correspond with the sort of steady state vision of a forest described above, indeed arguably just the opposite. Many of these smallholders on the edge of the forest are interested in moving the land into farming, and thus engaging in one-time cuts that will not be followed by replanting and later timber harvesting. In fact, this finding of negative supply elasticities is a sideshow in this study, which is more interested in such things as how the opening of the Transamazon highway, settlement regimes, and improvements in the availability of credits for these forester-farmers affect their behavior. As a result, the authors offer only limited explanation of the phenomenon they empirically observe, comparing it to what happens when labor supply curves bend backwards due to income effects overwhelming substitution effects. In their conclusion they state, "The timber price effect follows from the fact that the smallholder may have predetermined revenue targets that timber sales are intended to help meet" (ibid., p. 1796). They also find that informal holders of land do not exhibit these negative elasticities, although they do not provide an explanation for this finding.

The possibility of backward-bending supply curves for renewable natural resources has long been recognized in the literature (Copes, 1970; Clark, 1990; Hommes and Rosser, 2001), although this has usually focused on the specific example of fisheries, with this possibility widely recognized for them and even seen as an explanation for the widespread occurrence of fishery collapses. That this may also be possible for forests has been only occasionally observed for forests, with probably the first such observation being by Hyde (1980). Inspired particularly by the work of Colin W. Clark, Clark Binkley (1993) proposed a formal model for timber supply based on Faustmann, and also presented tentative evidence that this may apply to the long run supply of loblolly pine timber in the US Southeast. 
Using the variables we have defined already, we present Binkley's model below, adding only $\pi(t)$ for the net present value of the future stream of timber receipts, which the forest owner will seek to maximize. Of course in this analysis price will be allowed to change, in contrast to our earlier discussion. Interestingly in terms of our broader discussion, Binkley presents what could be a steady state forest, one on a fixed land area with multiple ages, although the results are more general not requiring an exact steady state. In any given year, trees will be harvested that reach the optimal rotation age, $T$, and the analysis will be in terms of the long run supply of timber per unit area arising from this, even if arguably it would be optimal to move the forest to be totally homogeneous in terms of age.

The forest owner seeks to

$$
\operatorname{Max} \pi(t)=-c+p f(t) e^{-r t}+\pi(t) e^{-r t}
$$

The first order conditions for this problem involve solving for $d \pi / d t=0$, which are given by

$$
f^{\prime}(t) /[f(t)-c / p]=r /\left(1-e^{-r t}\right)
$$

This implies a long run supply relationship that runs from price through the optimal rotation age, $\mathrm{T}$, given by

$$
S(p)=f(T(p)) / T(p)
$$

From this one gets a non-monotonic supply curve as a function of $\mathrm{T}$ that goes from zero to zero as $\mathrm{T}$ increases, with a maximum sustained yield (MSY) at an intermediate value of T given by

$$
1 / T=f^{\prime}(T) / f(T)
$$

From this it is possible then to derive the relationship between the price and the optimal rotation age $T$ that appears in (4), and given by 


$$
P=c /\left\{f(T)-f^{\prime}(T)\left[\left(1-e^{-r t}\right) / r\right]\right\}
$$

This is summarized in Figure $4 .^{6}$

\footnotetext{
${ }^{6}$ Variables in this figure reflect those used by Binkley, translating to this paper gives $v=f, t=T$, and $I=r$.
} 


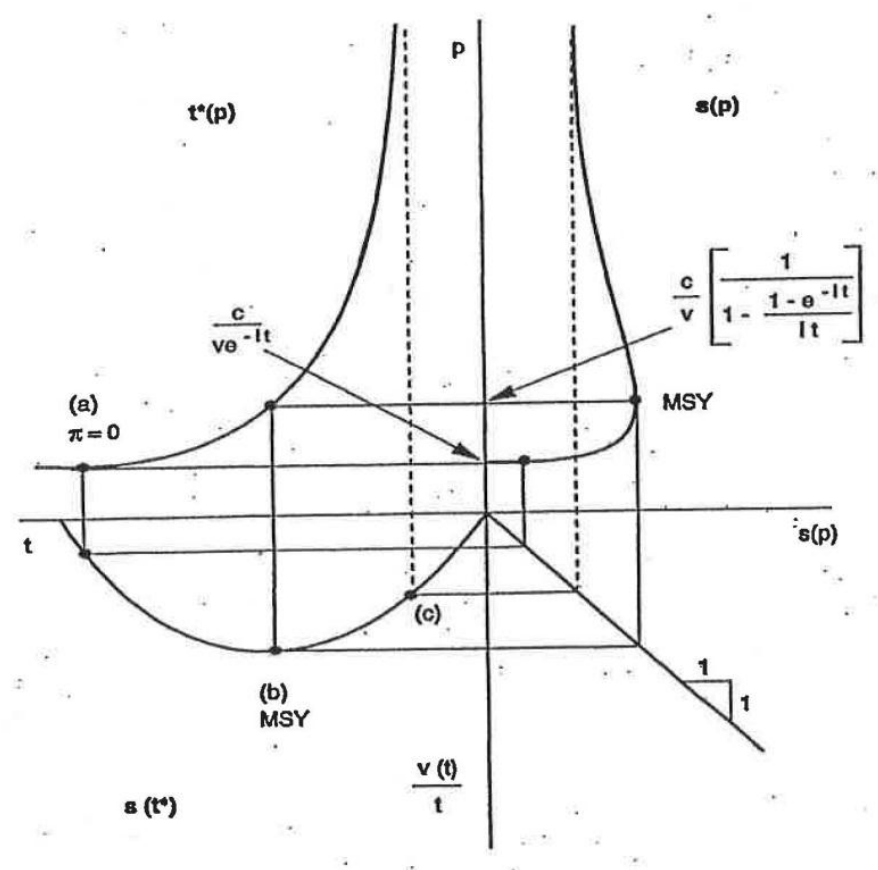

Figure 4: The Backward-Bending Long Run Supply of Timber 
For comparison purposes, we present the standard figure that appears in many studies of

fisheries, this particular one from Hommes and Rosser (2001). We note that $X$ is the biomass of fish, and $Q$ is the steady state harvest of fish that equals supply. The analysis of this draws on the study of open access fisheries by Gordon (1954), the basic fishery yield function by Shaeffer (1957), and the synthesis due to Clark (1990). 


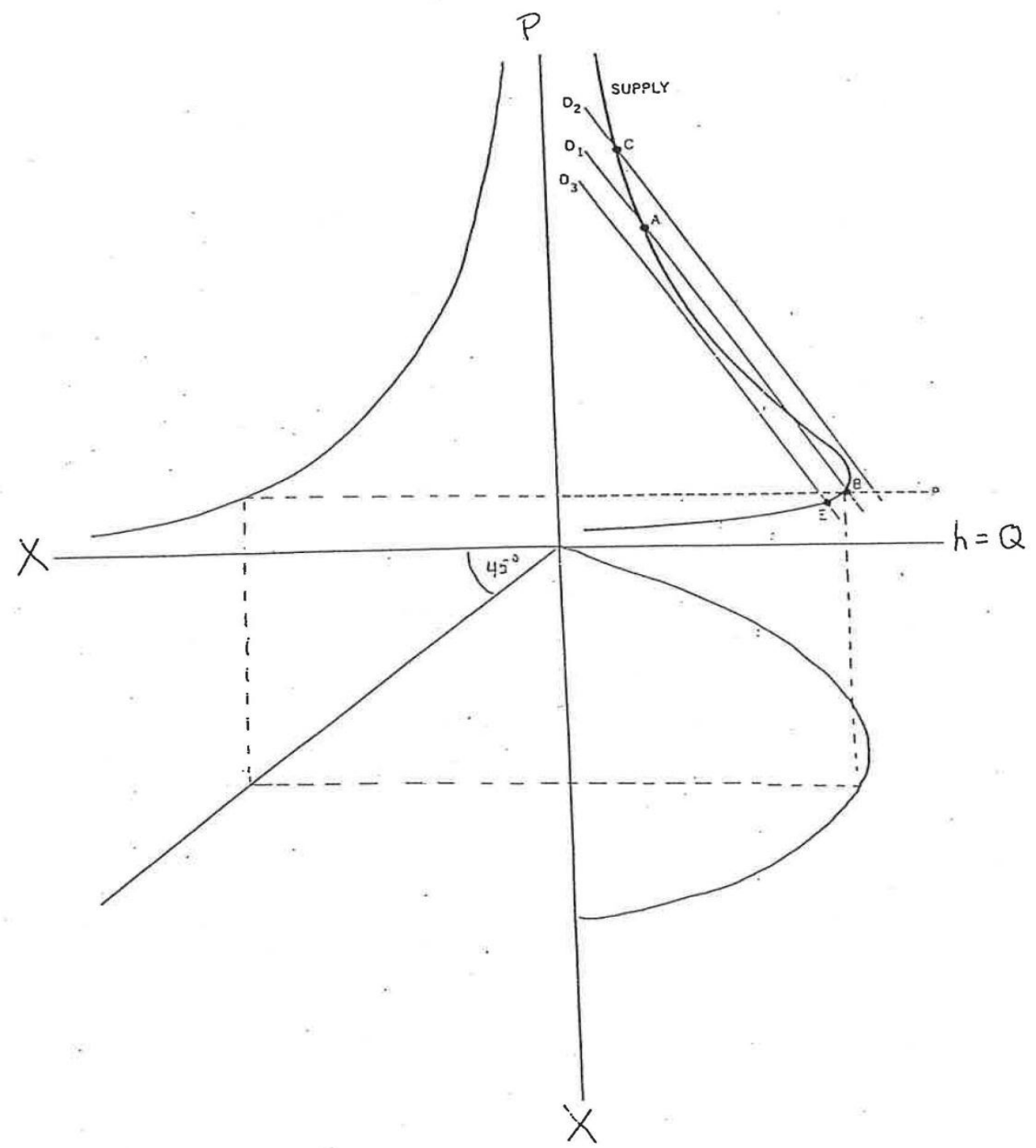

Figure 5: Backward-Bending Supply Curve for Fish 
We note some interesting parallels as well as some differences. Crucial to both of these is the assumption of a maximum carrying capacity, given by the fixed land area for the forestry. Both have only have three effective figures in them, with one quadrant simply presenting a 45 degree line, between rotation age for the forest and fish biomass for the fishery. Both have a fundamental nonmonotonic function that lies behind the backward-bend of the supply curve. For the fishery it is the Schaeffer yield function of steady state fish harvest and fish biomass, and for the forest it is timber supply as a function of rotation age. In both cases the maximum of that function gives the maximum sustained yield (MSY) derived from the growth function of the resource, and this point is what is associated with the maximum supply point of the supply curve, the point at which it bends backwards after sloping upwards in the standard fashion. While there has been much less discussion of these possible backward-bending supply curves in forests, the logic is very similar to that of what explains them for fisheries.

Intuitively what is going on in both cases is that the upward-sloping portion of the supply curve is associated with the "outer" portion of the yield function, that beyond the MSY point. For the fishery, this is where there are lots of fish so that they can be caught easily at a low cost, which can be covered by a low price. For the forest, this is for rotation periods longer than that associated with the maximum sustained yield. In both cases, in effect what happens as price rises is that the system slides up the relevant yield function towards its MSY point. The other side of that point is where the backwardbending portion of the supply curve derives from. For the fishery, there are few fish, so higher prices are associated with catching the ever costlier fewer ones that are there. For the forestry, this is associated with a much shorter rotation period that is associated with not allowing the trees to grow to their larger potential sizes before cutting them, thus getting smaller amounts of timber out of the approximately steady state harvests. 
In his conclusion, Binkley summarizes it thusly (p. 178):

"High stumpage prices imply not only that the output from the forest has a high value, but also that capital in the form of growing stock has a high opportunity cost. At high prices, it is optimal to conserve on the use of capital and therefore to reduce the growing stock inventory by reducing the rotation age."

There is one more important point that we need to observe, but is not discussed by Binkley or anybody else studying this matter for forests. It is the role of the discount rate or real interest rate. In the case of the fishery, the supply curve will only bend backwards if the discount rate is strictly positive. Indeed, for the undiscounted case, there will be no backward bend. What will happen is that the supply curve will simply asymptotically approach the vertical axis associated with the MSY level of output. More generally, the higher the discount rate, the more that the supply curve will bend backward. The most extreme case is that when the discount rate is infinite, meaning that decisionmakers are completely uninterested in the future of the fishery or forest and only want to maximize production today. This corresponds to the case of the open access fishery and will be associated with the supply curve bending backwards the maximum possible amount. This will maximize the possibility of multiple equilibria and the associated possible instabilities and catastrophic discontinuities. ${ }^{7}$ While for fisheries such a discontinuity arising from a steadily increasing demand implies the collapse of the fishery, for a forest this could result in a sudden bout of deforestation without proper replanting. ${ }^{8}$

\footnotetext{
${ }^{77}$ Other sources of discontinuities in forestry dynamics can arise due to pest outbreaks associated with the tradeoff between stability and resilience (Holling, 1973; Ludwig et al., 1978). These issues become associated with hierarchy dynamics in forests as well as problems of forest fire management (Holling et al., 2008). See also Rosser (2005; 2008; 2011, Chap. 9).

${ }^{8}$ For certain zones of the discount rate, Hommes and Rosser (2001) show the possibility of chaotic dynamics for a discrete period fishery. Khan and Piazza (2011) show this for the forestry case as well, linking this to the earlier
} 


\section{The Problem of Discount Rates for Forest Management Reconsidered}

As presented in the previous section, the shape of the supply curve for timber may well be backward-bending. The further backwards it bends the more likely is the outcome that there may be multiple equilibria. Once there are multiple equilibria, then the more possible it is that there may be a catastrophic collapse of a forest as there is a leap from an equilibrium showing lower price and higher quantity of timber supplied to one that has higher price and a lower quantity of timber supplied. This reality thus heightens the importance of the discount rate that is being used by those managing the forest in their analysis of how to do so, as we have also seen that the higher is the discount rate, the more likely it is that the supply curve will bend backwards sufficiently to bring about this result. Thus we are interested in how this discount rate comes to be determined.

For a purely commercial forest owner in a more developed market economy, it is quite likely that rate will be one from derived from the financial markets, a real interest rate based on a nominal rate minus the expected rate of inflation as Irving Fisher posed it. However, this does not definitively produce an answer that our forester will use. While most likely the nominal rate will correspond with some longer term rate in the financial markets, such as a 30 -year bond rate if such is the longest term one observes for any security in the market as is the case in many modern economies, there may be more than one kind of financial asset that exhibits such a maturity, such as government bonds and mortgages, whose nominal interest rates rarely equal each other. ${ }^{9}$ On top of that, there is no reason to expect in the real world any commonality of inflation expectations, even if many economic models effectively do so by assuming rational expectations on the parts of agents, which would mean at least

studies by Mitra (1996) and Nishimura and Yano (1996) finding chaotic dynamics in optimal trajectories with sufficiently high discount rates.

${ }^{9}$ Conventionally US government securities have been viewed as riskless, although downgrades of these raise questions about this and at times certain corporate bonds have had lower interest rates than US government securities of equal maturity. 
that on average they would accurately predict future inflation. However, this does not give us a definite answer regarding what any individual forester might be using in her calculations.

Once we move to a case where either there are multiple NTFPs or the decisionmakers are not primarily focused on the commercial sale of timber in managing their forests, the possible variations increase compared with this previous case. One aspect is simply that the NTFPs may be coming in at different time patterns than the timber, as discussed above, although this will presumably not be the case if one is dealing with a strictly steady state forest, which should generate a steady stream of all amenities from the forest over time. However, if this is not the case, and the forester is selling these other products on markets, it might be reasonable to consider shorter term interest rates for those products that are expected to arrive sooner than the timber. However, to the extent that selling on markets is more of a secondary concern, the relevant discount rate (or rates) may be more purely internal or psychological, and if a group is involved then it may reflect some aggregation of the internal or psychological rates for the individuals in the group, depending on their decisionmaking process.

Although the idea that the appropriate rate might vary depending on the time horizon of when products may arrive, this is not the standard view for models of time consistent optimization. For such the agent will use a single discount rate that presumably is based on a subjective time preference rate, but that will be constant over all time horizons. This leads to exponential discounting over whatever time horizon the agent is using for optimizing in terms of present value determination for the expected future stream of real net benefits. The time consistency implied by this means that the agent should not find herself altering behavior over time or experiencing regret over time. This will not hold if the agent uses different discount rates for different time horizons, what is broadly known as hyperbolic discounting, although this term is sometimes associated with a particular mathematical form for how the discount rate will vary over time horizons. 
In any case, there are strong reasons to believe that people internally use different discount rates to evaluate different time horizons, an idea first proposed by Strotz (1956). Whereas standard term structures of interest rates in markets usually exhibit higher nominal interest rates for longer maturity securities (often attributed to higher risk as maturity increases), the usual pattern ascribed to people making internal evaluations, and now strongly supported by many empirical studies, beginning with that of Hausman (1979) regarding consumer purchases of energy efficient appliances, is that people use higher rates for shorter time horizons and lower ones for longer time horizons, with the latter often approaching market rates. A classic form for such a time pattern of discount rates is due to Loewenstein and Prelec (1992) and is given by

$$
\alpha(t)=h \ln (1+g t) / g \ln (1+r)
$$

where $\alpha(t)$ is the discount rate used for time $t, h$ is the length of each perceived period of time, $g$ determines the degree to which a given discount rate deviates from what would hold under exponential discounting, and $r$ is the rate that would be used under exponential discounting. ${ }^{10}$ However, this is not the only such form that might be used by an agent, and a common variation on this is to have the shortest term discount rate be much higher than suggested by (7), followed by a sharp, possibly even discontinuous decline as the horizon increases, consistent with an apparent tendency by many people to have an especially high concern for events in the immediate future.

Evidence that most people discount hyperbolically at least to some extent is substantial and comes from a variety of sources. Among those are neurological studies that find that different parts of the brain tend to be involve when people are thinking about shorter versus longer term horizons (McClure et al., 2004; Kim and Zauberman,2009). That this may be evolutionarily founded is supported

\footnotetext{
${ }^{10}$ Rubinstein (2003) accepts that people do psychologically experience different rates of time discount over different time horizons, but objects to putting this into specific functional forms on the argument that imposing such specific forms "misses the core of the psychological decisionmaking process" (p. 1215).
} 
by experimental evidence that other species also exhibit some degree of hyperbolic discounting (Sherwood et al., 2008). Thinking about near term horizons tends to occur in regions of the brain associated with "fight or flight" decisions as well as reproductive ones, where immediate survival or some immediate reward is paramount. In humans longer term decisions are more likely to be found occurring in the prefrontal cortex where supposedly "rational" economic decisionmaking is going on.

Ainslie (1992) invented the term picoeconomics for thinking about how humans behave when they use some form of hyperbolic discounting. He observes that intelligent individuals will recognize that this is true about themselves and that this means that future selves will experience regret about decisions they may make in the near term due to the associated time inconsistency (Ainslie, 2005). This effectively means that an agent effectively has multiple selves that must negotiate with each other to come to decisions, with this negotiation often taking the form of an agent determining a plan for either "self-control" that will make nearer term decisions more acceptable to future selves or to prepare to accept the regret that will be felt by the future selves. As it is, to the extent that forest managers are following such discounting, they may end up effectively using much higher discount rates than would be used from relying on market determined ones alone, with the likely consequences of more likelihood of more rapid harvesting of timber and possible deforestation. This problem may be exacerbated when the forest managers are very poor and may thus have high operative discount rates.

Alternatively, particularly if a forest is being managed by a public or group entity, there may be an effort to use some sort of broader social discount rate. That such rates may not equal market interest rates has long been argued on a variety of grounds (Marglin, 1963), including those of intergenerational externalities, with the father of intertemporal optimization studies, Frank Ramsey (1928), going so far as to suggest that zero is the only ethically acceptable rate to use to overcome the 
problem of "telescopic myopia." ${ }^{11}$ It may be possible even if one agrees with Ramsey to still end up using positive discount rates if one takes account of the declining marginal utility of income and the expected future growth of the economy. Nevertheless, variations of hyperbolic discounting may yet offer another solution to the problem of concern regarding such externalities (Price, 2005).

Among those arguing for this latter position has been Graciela Chichilnisky (Chichilnisky et al., 1995), who has posed starting with something derived from a market rate for the shorter time horizon, but then having the rate decline towards zero as the time horizon moves into the distant time horizon, with this being particularly advocated for use in considering problems related to climate change. Chichilnisky proposes an ethical principle underlying this approach as being the green golden rule. This is posed as implying that on the one hand the present generation should not unfairly exploit future generations, while at the same time future generations should not unfairly exploit those currently alive. The former concern is satisfied by the use of very low discount rates for far distant time horizons, thus allowing for events in the distant future to still enter into current decisionmaking, whereas the latter concern is satisfied by the use of higher discount rates for shorter time horizons that insure that nearer term effects of interest to the current population are accounted for properly (and that nearer term investment should reflect the efficiency imperatives of the shorter term capital markets).

Unfortunately, neither Chichilnisky nor anybody else has come up with a definitive single system for determining what is essentially a normative judgment inherent in this approach.

We note three further points on this. One is that there is a potential ambiguity regarding discount rates for intertemporal analysis of renewable natural resources generally, including forests. This arises due to the role of real interest rates in determining the capital-intensivity of the harvesting or extraction technologies used in dealing with such resources. Thus, while a lower discount rate may

\footnotetext{
${ }^{11}$ While basically following Ramsey's dictum, Stern (2007) used a discount rate slightly above zero in his analysis of global warming policies on the basis of allowing for the gradually rising possibility of the extinction of the human species as time passes into the future.
} 
encourage more focus on future returns, it can also lead to a more capital-intensive technique being used that may end up harvesting the resource more intensively than would have otherwise been the case (Farzin, 1984). This has been specifically argued as particularly relevant for fisheries (Hannesson, 1987) and is reflected in the quotation by Binkley reported above. Regarding forests, it is less obviously the case, although the move towards greater use of large-scale clearcuts in modern timber harvesting, which many find undesirable on externality grounds, may be partly driven by the cost advantages associated with the use of more capital intensive machinery in the timber harvesting process.

The second point returns us to the matter of governance and control and to concerns particularly studied by Elinor Ostrom (1990), particularly when we are dealing with forests controlled by traditional groups in developing nations. How successful are these groups at organizing themselves to manage the forest and to control access to it? She has argued that often traditional systems of management are often superior in this regard, and that these have done better in some nations, such as Nepal, at preserving forests compared to ones that are run by corporations for market purposes or by nationalized entities within a presumably socialist context. This may well be true if these latter two end up being associated with uncontrolled poaching and uncontrolled use by local populations who are excluded from the decisionmaking and resent the intrusion of these essentially outside entities into their territory.

Again we must emphasize that the open access solution is effectively identical to one that is optimizing using an infinite discount rate in which the future does not matter at all. We know that this solution is associated with the greatest degree of backward bending of the supply curve. This then means that the open access solution is most likely to be associated with multiple equilibria and the associated instabilities and discontinuities that may involve the kinds of deforestation that have indeed been observed not only in Nepal but in many parts of the world. We shall not get into how groups 
overcome these problems in order to cooperate to avoid such outcomes, but there is an enormous literature on this, much of it inspired by the work of Ostrom and her associates. ${ }^{12}$

Finally, we pose the idea of the steady state forest as an ideal that may resolve many of the problems of exernalities and sustainability that have long concerned many observers. The main problem with this solution is that it often involves higher costs than the more standard approach of cutting and replacing at given intervals an entire forest. However, this may be more a matter of scale of control and sizes of clearcutting. Even in the steady state forest, one will presumably not be just cutting one tree here and one tree there as in some idealized silvicultural paradise. Rather what is involved is indeed having some structure of the forest where there are patches of trees of approximately homogeneous age. This then becomes a matter of determining this patch structure and the sizes of these patches, with then some harvesting occurring each year as the overall larger forest is maintained as something approaching a steady state in its overall structure. After all, there is no truly steady state in any forest, as any individual tree will grow and eventually die. All that can be kept as stationary is some overall pattern or structure.

\section{Conclusions}

This paper has considered problems of forestry management, with a focus on problems associated with intertemporal issues. These issues can arise from a variety of sources. These include complicated time patterns of the amenities generated by non-timber forest products. They also appear due to higher discount rates possibly leading to backward-bending supply curves for timber in optimal rotation situations. They can also arise due to the ambiguities associated with determining what the appropriate discount rate to use is, with such possibilities as different ones being used for different time horizons, whether from arising from internal hyperbolic discounting or due to normative considerations

\footnotetext{
${ }^{12}$ These situations often can be viewed as prisoner's dilemma game. Traditional customs can reinforce norms that encourage cooperative solutions (Sethi and Somanathan, 1996).
} 
carried out by decisionmakers who may be worried about intergenerational externalities, with such solutions as the green golden rule paralleling the hyperbolic discounting that individuals may experience. While there are various ambiguities associated with changes in discount rates, dynamic complexities, including the possibility of catastrophic deforestation, may be associated with the use of higher discount rates, which may be associated with difficulties in ownership and governance patterns of forest systems.

One idea arising from this analysis may be that steady state forests may offer a possible solution to some of these issues, particularly related to longer term sustainability. Such outcomes may not correspond with optimal intertemporal patterns of forest management in terms of maximizing the present value of market future returns. However, such outcomes may help towards solving a broader array of problems associated with managing forests, particularly in developing countries with traditional populations. These steady state patterns may also be less susceptible to some of the problems investigated in this paper regarding valuing time and allocating over time.

\section{References}

Ainslie, George. 1992. Picoeconomics. Cambridge: Cambridge University Press.

Ainslie, George. 2005. "Précis of Breakdown of Will." Behavioral and Brain Sciences 28, 635-673.

Alchian, Armen A. 1952. Economic Replacement Policy. Santa Monica: RAND Corporation.

Amacher, Gregory S., Frank D. Merry, and Maria S. Bowman. 2009. "Smallholder timber sale decisions on the Amazon frontier." Ecological Economics 68, 1787-1796.

Arrow, Kenneth J. and Anthony C. Fisher. 1974. "Preservation, uncertainty and irreversibility." Quarterly Journal of Economics 87, 312-319.

Asheim, Geir B. and Wolfgang Buchholz. 2005. "Can stock-specific sustainability constraints be justified?" In Kant and Berry, pp. 175-189.

Binkley, Clark S. 1993. "Long-run timber supply: price elasticity, inventory elasticity, and the use of capital in timber production." Natural Resource Modeling 7, 163-181. 
Caparrós, A. and F. Jacquemont. 2003. "Conflicts between biodiverslity and carbon sequestration programs: Economic and legal implications." Ecological Economics 46, 143-157.

Chichilnisky, Graciela, Geoffrey Heal, and Andrea Beltratti. 1995. "The green golden rule." Economics Letters 49, 175-179.

Clark, Colin W. 1990. Mathematical Bioeconomoics, $2^{\text {nd }}$ edition. New York: Wiley-Interscience $\left(1^{\text {st }}\right.$ edition, 1976, same publisher).

Copes, Parzival. 1970. "The backward-bending supply curve of the fishing industry." Scottish Journal of Political Economy 17, 69-77.

Farzin, Y. Hossein. 1984. "The effect of the discount rate on the depletion of natural resources." Journal of Political Economy 92, 841-851.

Faustmann, Martin. 1849. "Berechnumg des werthes, welchen waldboden, sowie noch nicht haubare holzbestande für die waldwirtschaft besitzen." Allgemeine Forst und Jagd-Zeitung 25, 441-455. English translation by W. Lennard, 1968, "On the determination of the value which forest land and immature stands possess for forestry." In M. Gane (Ed.) Martin Faustmann and the Evolution of Discounted Cash Flow. Commonwealth Forestry Institute Paper 42, Oxford University.

Fisher, Irving. 1907. The Rate of Interest. New York: Macmillan.

Gaffney, Mason. 1957. "Concepts of financial maturity of timber and other assets." Agricultural Economics Information Series 62. Raleigh: North Carolina State College.

Gordon, H. Scott. 1954. "Economic theory of a common-property resource: The fishery." Journal of Political Economy 62, 124-142.

Gowdy, John, J. Barkley Rosser, Jr., and Loraine Roy. 2012. "The evolution of hyperbolic discounting: Implications for truly social valuation of the future." Mimeo, http://cob.jmu.edu/rosserib.

Gram, S. 2001. "Economic valuation of special forest products: An assessment of methodological shortcomings." Ecological Economics 26, 109-117.

Hannesson, Rognvalder. 1987. "The effect of the discount rate on optimal exploitation of renewable resources." Marine Resource Economics 3, 319-329.

Hartman, Richard. 1976. "The harvesting decision when a standing forest has value." Economic Inquiry $14,52-58$.

Hausman, Jerry A. 1979. "Individual discount rates and the purchase and utilization of energy using durables." Bell Journal of Economics 10, 33-54.

Holling, C.S. 1973. "Resilience and stability of ecological systems." Annual Review of Ecology and Systematics 4, 1-24.

Holling, C.S., Garry D. Peterson, and Craig R. Allen. 2008. "Panarchies and hierarchies." In C.R. Allen and C.S. Holling (Eds.), Discontinuities in Ecosystems and Other Complex Systems. New York: Columbia University Press, pp. 3-19. 
Hommes, Cars H. and J. Barkley Rosser, Jr. 2001. "Consistent expectations equilibria and complex dynamics in renewable resource markets." Macroeconomic Dynamics 5, 180-203.

Hyde, W.F. 1980. Timber Supply, Land Allocation, and Economic Efficiency. Baltimore: Johns Hopkins University Press.

Johnson, K.N., D.B. Jones, and B.M. Kent. 1980. A User's Guide to the Forest Planning Model (FORPLAN). Fort Collins: USDA Forest Service, Land Management Planning.

Kant, Shashi. 2000. A dynamic approach to forest regimes in developing countries." Ecological Economics 32, 287-300.

Kant, Shashi. 2003. "Extending the boundaries of forest economics." Journal of Forest Policy and Economics 5, 39-58.

Kant, Shashi. 2005. "Post-Newtonian Economics and Sustainable Forest Management." In Kant and Berry, pp. 253-267.

Kant, Shashi and R. Albert Berry (Eds.). 2005. Economics, Sustainability, and Natural Resources: Economics of Sustainable Forest Management. Dordrecht: Springer.

Khan, M. Ali. 2005. "Inter-temporal ethics, modern capital theory, and the economics of sustainable forest management." In Kant and Berry, pp. 39-66.

Khan, M. Ali and Adriana Piazza. 2011. "Optimal cyclicality and chaos in the 2-sector RSS model: An anything-goes construction." Journal of Economic Behavior and Organization 80, 397-417.

Khan, M. Ali and Adriana Piazza. 2012. "On the Mitra-Wan forestry model: A unified analysis." Journal of Economic Theory 147, 230-260.

Kim, B. and G. Zauberman. 2009. "Perception of anticipatory time in temporal discounting." Journal of Neuroscience, Psychology, and Economics 2, 91-101.

Loewenstein, George and Drazen Prelec. 1992. "Anomalies in intertemporal choice: Evidence and an interpretation." Quarterly Journal of Economics 107, 573-597.

Ludwig, Donald, Dixon D. Jones, and C.S. Holling. 1978. "Quality analysis of insect outbreak systems: The spruce budworm and the forest." Journal of Animal Ecology 47, 315-332.

Marglin, Stephen A. 1963. "The social rate of discount and the optimal rate of investment." Quarterly Journal of Economics 77, 95-111.

McClure, Samuel M., David Laibson, George Loewenstein, and Jonathan D. Cohen. 2004. "Separate neural systems value immediate and delayed monetary rewards." Science 306, 503-507.

Mitra, Tapan. 1996. "An exact discount factor restriction for three-period cycles in dynamic optimization models." Journal of Economic Theory 69, 281-305.

Mitra, Tapan and H.J. Wan, Jr. 1986. "On the Faustmann solution to the forest management problem." Journal of Economic Theory 40, 229-249. 
Nishimura, Kazuo and M. Yano. 1996. "On the least upper bound on discount factors that are compatible with optimal period-three cycles." Journal of Economic Theory 69, 306-333.

Ostrom, Elinor. 1990. Governing the Commons: The Evolution of Institutions for Collective Action.

Cambridge: Cambridge University Press.

Plantinga, A.J. and J. Wu. 2003. "Co-benefits from carbon sequestration in forests: Evaluating reductions in agricultural externalities from an afforestation policy in Wisconsin." Land Economics 79, 74-85.

Price, Colin. 2005. “How sustainable is discounting?" In Kant and Berry, pp. 105-135.

Prince, Raymond and J. Barkley Rosser, Jr. 1985. "Some implications of delayed environmental costs for benefit-cost analysis: A study of reswitching in the western coal lands." Growth and Change 16, 18-25.

Ramsey, Frank P. 1928. "A mathematical theory of saving." Economic Journal 38, 543-549.

Reed, W.J. and H.R. Clarke.1990. "Harvest decision and asset valuation for biological resources exhibitinnng size-dependent stochastic growth.” International Economic Review 31, 147-169.

Rosser, J. Barkley, Jr. 2005. "Complexities of dynamic forest management policies." In Kant and Berry, pp. 191-206.

Rosser, J. Barkley, Jr. 2008. "Dynamic discontinuities in ecologic-economic systems." In C.R. Allen and C.S. Holling (Eds.),Discontinuities in Ecosystems and Other Complex Ecosystems. New York: Columbia University Press, pp. 179-192.

Rosser, J. Barkley, Jr. 2011. Complex Evolutionary Dynamics in Urban-Regional and Ecologic-Economic Systems: From Catastrophe to Chaos and Beyond. New York: Springer.

Rubinstein, Ariel. 2003. "Economics and psychology? The case of hyperbolic discounting." International Economic Review 44, 1207-1216.

Samuelson, Paul A. 1976a. "Economics of forestry in an evolving society." Economic Inquiry 14, 147-169.

Samuelson, Paul A. 1976b. "The periodic turnpike theorem." Nonlinear Analysis, Theory,Methods and Applications 1, 1-13.

Schaeffer, M.B. 1957. "Some considerations of population dynamics and economics in relation to the management of marine fisheries." Journal of the Fisheries Research Board of Canada 14, 669-681.

Sethi, Rajiv and Eswaran Somanathan. 1996. "The evolution of social norms in common property use." American Economic Review 86, 766-788.

Sherwood, C., F. Subial, and T. Zadiski. 2008. "A natural history of the human mind: Tracing evolutionary changes in brain and cognition." Journal of Anatomy 212, 426-454.

Stern, Nicholas. 2007. The Economics of Climate Change: The Stern Review. Cambridge: Cambridge University Press.

Stockfish, Jacob A. 1969. Measuring the Opportunity Cost of Government Investments. Washington: Institute for Defense Analysis. 
Strotz, Robert H. 1956. "Myopia and inconsistency in dynamic utility maximization." Review of Economic Studies 23, 165-180.

Swallow, S.K., P.J. Parks, and D.N. Wear. 1990. "Policy-relevant non-convexities in the production of multiple forest benefits." Journal of Environmental Economics and Management 19, 264-280. 